\title{
Comparison of the Ultrasonic Evaluation of Bi-Parietal Diameter and Femoral Length in 2nd and 3rd Trimester to Estimate the Gestational Age
}

*Akter $\mathrm{F}^{1}$, Uddin $\mathrm{B}^{2}$, Ahmed $\mathrm{M}^{3}$, Begum $\mathrm{KN}^{4}$, Akter $\mathrm{N}^{5}$, Sultana $\mathrm{S}^{6}$, Wahab MA7 , Nila TA ${ }^{8}$, Shaheen MMR ${ }^{9}$, Habib RB ${ }^{10}$

\begin{abstract}
During the gestational period, fetal biometrics are assessed through ultrasonography to observe the growth of the fetus. This study observed the corresponding of gestational age those were measured by two of the fetal diameters; gestational age were calculated from history of last menstrual period (LMP), in the last two trimesters. This descriptive type of observational study was carried out in the Department of Radiology and Imaging of Dhaka Medical College and Hospital, during the period of July, 2004 to June, 2005. Here 291 single-ton, non-complicated pregnant women of LMP were selected purposively from valid record. Bi-parietal diameter (BPD) and femoral length (FL) estimated through ultrasonography. These two parameters compared with the gestational age in
\end{abstract}

1. * Dr. Farjana Akther, Assistant Professor, Dept. of Radiology \& Imaging, National Institute of Mental Health \& Hospital (NIMH), Dhaka. Email: aktherfarjana509@gmail.com

2. Dr. Borhan Uddin, Assistant Professor, Dept. of Radiology \& Imaging, Kurmitola General Hospital, Dhaka.

3. Dr. Mahbuba Ahmed, Associate Professor, Dept. of Radiology \& Imaging, NIMH, Dhaka.

4. Dr. Kazi Nazma Begum, Assistant Professor, Dept of Gynae and Obs. Mugda Medical College (MuMC), Dhaka.

5. Dr. Nasrin Akhter, Assistant Professor, Dept. of Psychiatry, MuMC, Dhaka.

6. Dr. Shiren Sultana, Associate Professor Dept. of Gynae \& Obstetrics, Munno Medical Collage \& Hospital

7. Mohammad Abdul Wahab, Asisstent Professor Dept. of Anaethesiology, Saheed Sayed Nazrul Islam Medical College (SSNIMC), Kishoreganj

8. Dr. Taslim Ara Nila, Junior Consultant, (Gynae and Obstetrics), SSNIMC, Kishoreganj.

9. Dr. Md. Mahbubur Rahman Shaheen, Asisstent Professor (Ophthelmology), President Abdul Hamid Medical College Hospital, Kishoreganj.

10. Dr. Rahat Bin Habib, Assistant Professor Dept. of Pediatrics, SSNIMC, Kishoreganj.

${ }^{*}$ For correspondence second and third trimester. The study found that, before $36^{\text {th }}$ week, the BPD based gestational age varied 2 to 3 days from $L M P$ based gestational age and after that, the variation was 1 to 4 weeks. In case of FL, the ultrasonic measurement found to be 2 to 4 days backward in the second trimester and 2 to 3 days advance in the last trimester in contrast to the LMP based gestational age. In the second trimester, it has been found that, $B P D$ has been the superior predictor of the gestational age than the FL with the correlation coefficient of 0.999 in case of BPD and 0.998 in case of FL when correlated with LMP based gestational age. Although, in third trimester, FL versus BPD predicted the gestational age with a correlation coefficient of 0.998 versus 0.978 respectively, when correlated with gestational age based on the history of LMP. This study has observed that, later in pregnancy, FL has the better predictability over BPD to determine the gestational age.

Keywords: Gestational age, bi-parietal diameter (BPD), femoral length (FL), last menstrual period (LMP)

\section{INTRODUCTION}

Ultrasonic determination of the age of the fetus is one of the most common routine examination any women undergoes during the course of their pregnancy period. Accurate assessment of the gestational age and estimated delivery date are specifically important for those pregnant women who have gestational complication and who may need early intervention, as for example- early cesarean section or to identify growth restriction ${ }^{1}$ also referred to as intrauterine growth restriction (IUGR History of LMP alone is quite undependable in these cases, as because there remain the chance of incorrect dating of the last menstruation and/or history of irregular menstruation., ${ }^{2,3}$ Fetal age estimation as well as growth observation through diagnostic ultrasonography is widely dependent on fetal biometry. ${ }^{4}$ Ultra-sonographic measurement of various fetal anatomic structures persistently remained the most constant method to determine the gestational age owing to its non-invasive technique and well tolerance of repetitive use. ${ }^{5-7} 67$ twin, and 19 triplet gestations resulting from in vitro fertilization with ultrasonographic fetal biometry from 14 to 22 weeks made up the study population. A 
gestational age prediction equation was derived from singletons with the use of stepwise linear regression. This equation was compared with 38 previously published equations and then applied to the twin and triplet populations.InRESULTS: Head circumference was the best predictor of gestational age (random error [SD] 3.77 days Among the fetal biometric measurements, bi-parietal diameter and femur length remained the most popular. ${ }^{1}$ also referred to as intrauterine growth restriction (IUGR Bi-parietal diameter (BPD) has been widely used to estimate the gestational age, as this fetal dimension is dependably measurable even by the sonographers who are comparatively less experienced. ${ }^{1}$ also referred to as intrauterine growth restriction (IUGR This measurement estimates the gestational age at its best after 12 weeks of gestation. ${ }^{8}$ as ultrasound is safe, easy operating and cheap. Objectives: to predict the GA with BPD and FL, to derive equations from linear regression analysis of GA with BPD and FL this could be applied to determine the fetal GA, to compare between BPD and FL. Methods: there were 100 normal pregnancies (singleton However, in the last trimester BPD showed to have less consistency due to biological variability and because of an increased likelihood of discrepancy of the shape of the cranium due to position of the fetus, therefore, requires for additional biometric measurements to evaluate the growth of fetus and to avoid miscalculating the ultra-sonographic estimation of gestational age., ${ }^{9,10}$ Estimation of fetal age with the sonographic evaluation of femoral length has gained its wide acceptance due to its reproducibility of gestational age later in the final trimester. ${ }^{9}$ On the other hand, femoral length (FL) has gained its popularity over several other fetal biometric observation due to exhibiting better correspondence to gestational age, and study findings gave also suggested that FL to be significantly more accurate than other fetal measurements in late pregnancy. ${ }^{11} \mathrm{FL}$ is best to be measured after 14 weeks of gestation. ${ }^{12}$ Therefore, the present study is aimed to evaluate sonographic measurement of fetal bi-parietal diameter and femoral length to estimate the gestational age in second and third trimester to observe the correspondence to the gestational age calculated from the history of LMP.

\section{MATERIALS AND METHODS}

Subjects design: This descriptive type of observational study was conducted in the department of Radiology and Imaging of Dhaka Medical College and Hospital, during the period of July, 2004 to June, 2005. The study was included 291 single-ton, non-complicated pregnancy cases with 18 to 42 weeks of gestation having well defined record of last menstrual history before the pregnancy, BMI within normal range and history of regular menstruation cycle. Cases with obstetric complication with any other significant morbidity or congenital anomalies of the fetus were excluded. With prior ethical approval the study has been conducted. ritten informed consent was taken from each of the participant.

Gestational age: Gestational age was calculated by history of LMP and compared that with the sonographic evaluation of the gestational age determined by bi-parietal diameter (BPD) and femoral length (FL). Every fetus has been measured only once, and only a single measurement for each parameter was recorded. The bi-parietal diameters and femoral lengths were expressed in $\mathrm{mm}$, the gestational ages were presented in weeks. The sonographic evaluation was done using gray scale real time ultrasound scanner equipped with $3.5 \mathrm{MHz}$ convex transducer of $\mathrm{GE}$ LOGIQ $^{\mathrm{TM}}$ a 200 ultrasound machine, TOSHIBA, Just Vision 4000 and SIEMENS, SONOLINE G 20 ultrasound machine and Fukuda Denshi, FF SONIC, UF 4000 .

Measurement of bi-parietal diameter and: The BPD was measured by the 'leading edge to leading edge technique' by Palmer. ${ }^{13}$ The transverse section of the fetal skull was identified using scans at different angels. When the plane was found, where the fetal skull was in ovoid shape and the midline echo from the flax cerebri is interrupted by the cavum septi pellucidi and the thalami., then the gain in the ultrasound was reduced until the measurements from the outer table of the proximal skull to the inner table of the distal skull could be made. The soft tissue over the skull was excluded.

Measurement of femur length The FL was detected by the technique described by O'Brien, Queenan and Campbell. ${ }^{14}$ After identifying the fetal lying position, the transducer was placed at the right angel to the fetal spine, and maintaining the angle the transducer is passed down the fetus and the caudal end was reached. As the fetal femur is typically flexed, the transducer was then rotated from this position through 30 to 45 degrees toward the fetal abdomen until the full length of the femur could be captured and measurement was then taken without considering the flexion rather recorded as the straight measurement.

Statistical methods: All statistical analysis was carried out using the SPSS (Statistical Package for the Social Sciences) 
version 25 software (IBM Corp. Released 2017. IBM SPSS Statistics for Windows, Version 25.0. Armonk, NY: IBM Corp). Continuous data were presented as mean and standard deviation. The gestational age estimated by ultrasonic measurement of BPD and FL was correlated with the gestational age measured by the history of LMP in second and third trimesters by Pearson correlation considering the level of significance at $\mathrm{p}$ value less than 0.05 .

\section{RESULT}

The BPD and FL of 291 pregnant cases from 18 to 42 weeks have been expressed in $\mathrm{mm}$ and estimated gestational age was expressed in weeks, the number of fetus with the corresponding gestational age has been depicted in Table I and II. The gestational age estimated by ultrasonic measurement of BPD and FL has been compared with the gestational age measured by the history of LMP showed in Table I and II respectively.

Table I shows the estimated gestational age calculated by the history of LMP and gestational age measured from ultrasonic measurement of BPD observed to be in close in relation up to $35^{\text {th }}$ week, where the variation among these two parameters ranged between 2 to 3 days. After $35^{\text {th }}$ week of gestation, the variation between gestational age measured from BPD and from LMP observed to be 1 to 4 weeks.

Table I: Ultrasonic measurement of BPD to estimate gestational age and gestational age calculated from history of LMP

\begin{tabular}{|c|c|c|c|c|c|c|}
\hline \multirow{2}{*}{\multicolumn{2}{|c|}{$\begin{array}{l}\text { Estimation of } \\
\text { Gestational Age by } \\
\text { LMP history (in weeks) }\end{array}$}} & \multirow{3}{*}{$\begin{array}{c}\begin{array}{c}\text { Number } \\
\text { of Fetuses }\end{array} \\
10\end{array}$} & \multicolumn{2}{|c|}{$\begin{array}{l}\text { Bi-parietal } \\
\text { diameter }\end{array}$} & \multicolumn{2}{|c|}{$\begin{array}{l}\text { Ultrasonic Estimation of } \\
\text { Gestational Age by BPD }\end{array}$} \\
\hline & & & \multirow{2}{*}{$\begin{array}{l}\text { Mean } \\
40.64\end{array}$} & \multirow{2}{*}{$\frac{\text { SD }}{1.05}$} & \multirow{2}{*}{$\begin{array}{l}\text { Mean } \\
18.29\end{array}$} & \multirow{2}{*}{$\begin{array}{c}\text { SD } \\
0.04\end{array}$} \\
\hline \multirow{9}{*}{ Second Trimester } & 18 & & & & & \\
\hline & 19 & 11 & 43.97 & 0.76 & 19.34 & 0.34 \\
\hline & 20 & 11 & 47.86 & 0.62 & 20.43 & 0.27 \\
\hline & 21 & 12 & 50.28 & 1.01 & 21.39 & 0.36 \\
\hline & 22 & 11 & 54.02 & 1.08 & 22.41 & 0.34 \\
\hline & 23 & 12 & 56.2 & 0.75 & 23.35 & 0.38 \\
\hline & 24 & 13 & 59.23 & 0.08 & 24.37 & 0.33 \\
\hline & 25 & 12 & 62.53 & 0.56 & 25.41 & 0.36 \\
\hline & 26 & 13 & 65.01 & 0.85 & 26.39 & 0.39 \\
\hline \multirow{16}{*}{ Third Trimester } & 27 & 14 & 68.12 & 0.87 & 27.36 & 0.38 \\
\hline & 28 & 13 & 70.5 & 0.54 & 28.36 & 0.38 \\
\hline & 29 & 14 & 73.23 & 0.09 & 29.37 & 0.27 \\
\hline & 30 & 12 & 76.68 & 1.07 & 30.42 & 0.43 \\
\hline & 31 & 11 & 78.08 & 0.06 & 31.38 & 0.32 \\
\hline & 32 & 11 & 80.93 & 0.65 & 32.48 & 0.04 \\
\hline & 33 & 12 & 83.08 & 0.49 & 33.35 & 0.25 \\
\hline & 34 & 12 & 85.3 & 0.78 & 34.39 & 0.33 \\
\hline & 35 & 11 & 87.93 & 0.69 & 35.4 & 0.33 \\
\hline & 36 & 12 & 89.01 & 0.81 & 35.95 & 0.23 \\
\hline & 37 & 12 & 89.53 & 0.47 & 36.17 & 0.29 \\
\hline & 38 & 10 & 90.05 & 0.48 & 36.43 & 0.24 \\
\hline & 39 & 11 & 91.03 & 0.55 & 36.88 & 0.37 \\
\hline & 40 & 11 & 92.14 & 0.46 & 37.31 & 0.18 \\
\hline & 41 & 10 & 92.98 & 0.64 & 37.77 & 0.18 \\
\hline & 42 & 10 & 93.92 & 0.4 & 37.95 & 0.13 \\
\hline
\end{tabular}


Table II shows the gestational age measured from ultrasonic measurement of FL was 2 to 4 days behind from the estimated gestational age calculated by the history of LMP upto the $27^{\text {th }}$ week of gestation. After $27^{\text {th }}$ week gestational age measured from FL was 2 to 3 days advanced from gestational age measured from LMP

Table II: Ultrasonic measurement of FL to estimate gestational age and gestational age calculated from history of LMP

\begin{tabular}{|c|c|c|c|c|c|c|}
\hline \multirow{2}{*}{\multicolumn{2}{|c|}{$\begin{array}{l}\text { Gestational Age by } \\
\text { LMP history (in weeks) }\end{array}$}} & \multirow{3}{*}{$\begin{array}{c}\text { Number } \\
\text { of Fetuses }\end{array}$} & \multicolumn{2}{|c|}{$\begin{array}{c}\text { Femoral } \\
\text { Length }\end{array}$} & \multicolumn{2}{|c|}{$\begin{array}{c}\text { Ultrasonic Estimation of } \\
\text { Gestational Age by FL }\end{array}$} \\
\hline & & & Mean & SD & Mean & SD \\
\hline \multirow{9}{*}{ Second Trimester } & 18 & & 26.22 & 0.52 & 17.45 & 0.32 \\
\hline & 19 & 11 & 29.45 & 0.36 & 18.33 & 0.31 \\
\hline & 20 & 11 & 32.75 & 0.93 & 19.44 & 0.35 \\
\hline & 21 & 12 & 35.15 & 0.99 & 20.45 & 0.35 \\
\hline & 22 & 11 & 38.78 & 0.64 & 21.67 & 0.31 \\
\hline & 23 & 12 & 41.12 & 0.91 & 22.38 & 0.27 \\
\hline & 24 & 13 & 43.04 & 0.56 & 23.65 & 0.03 \\
\hline & 25 & 12 & 46.64 & 0.75 & 24.99 & 0.27 \\
\hline & 26 & 13 & 48.9 & 0.94 & 25.66 & 0.32 \\
\hline \multirow{16}{*}{ Third Trimester } & 27 & 14 & 51.58 & 0.66 & 26.87 & 0.35 \\
\hline & 28 & 13 & 53.97 & 0.96 & 28.29 & 0.04 \\
\hline & 29 & 14 & 56.27 & 0.54 & 29.37 & 0.04 \\
\hline & 30 & 12 & 59.25 & 0.81 & 30.39 & 0.32 \\
\hline & 31 & 11 & 61.15 & 0.46 & 31.36 & 0.29 \\
\hline & 32 & 11 & 63.02 & 0.56 & 32.36 & 0.03 \\
\hline & 33 & 12 & 64.79 & 0.62 & 33.29 & 0.21 \\
\hline & 34 & 12 & 67.61 & 0.76 & 34.32 & 0.44 \\
\hline & 35 & 11 & 69.81 & 0.89 & 35.39 & 0.27 \\
\hline & 36 & 12 & 71.86 & 0.56 & 36.37 & 0.42 \\
\hline & 37 & 12 & 73.15 & 0.47 & 37.29 & 0.35 \\
\hline & 38 & 10 & 75.68 & 0.54 & 38.35 & 0.32 \\
\hline & 39 & 11 & 77.52 & 0.62 & 39.37 & 0.34 \\
\hline & 40 & 11 & 79.49 & 0.52 & 40.29 & 0.33 \\
\hline & 41 & 10 & 80.89 & 0.62 & 41.24 & 0.03 \\
\hline & 42 & 10 & 82.82 & 0.29 & 42.26 & 0.42 \\
\hline
\end{tabular}

Table III shows pearson's correlation coefficient the LMP based gestational age and gestational age estimated from BPD was strongly significantly correlated with the correlation coefficient of 0.999 in the second trimester and in the third trimester it was $0.978(\mathrm{p}<0.001)$. In case of FL, the correlation coefficient was 0.999 in the second trimester and in the third trimester it was 0.998 and the association was strongly significant in both cases $(\mathrm{p}<0.001)$ 
Table III: Correlation of estimated gestational age by BPD and FL with estimated gestational age by history of LMP in second and third trimester

\begin{tabular}{|c|c|c|c|c|c|}
\hline \multirow[b]{2}{*}{ Trimesters } & \multirow[b]{2}{*}{$\mathbf{N}$} & \multicolumn{2}{|c|}{ BPD } & \multicolumn{2}{|c|}{ FL } \\
\hline & & $\mathbf{R}$ & P value & $\mathbf{R}$ & P value \\
\hline Second Trimester & 92 & .999 & 0.000 & .999 & 0.000 \\
\hline Third Trimester & 199 & .978 & 0.000 & .998 & 0.000 \\
\hline
\end{tabular}

\section{DISCUSSION}

Ultrasonic evaluation of the gestational age of the fetus is based on the known size of the fetus according to their age, which has been estimated from large scale studies on fetal growth, which gives rise to a standard growth chart particularly applicable for that population..$^{15}$ Due to the unpredictability of the gestational age calculated from last menstrual history of the pregnant woman, ultrasonic evaluation provides with indispensable significance to evaluate the growth of the fetus along with other developmental determinants. ${ }^{3,16}$ The genetic inheritance of the growth velocity as well as the maternal nutritional and environmental factors play significant role in the growth spurt of the fetus. ${ }^{17}$ Moreover, inconsistencies in gestational age assessment by the sonographic measurement of fetal biometrics also has been observed despite of the normal fetal growth. ${ }^{18}$ Thus, continuous researches in this field can aid in to understand it better about growth evaluation. Among the various fetal biometrics $\mathrm{BPD}$ and $\mathrm{FL}$ are the widely used ones to estimate fetal growth and age. Whereas BPD is an older one to be in use and FL is comparatively newer and has proven to be more accurate.

In the present study both BPD and FL estimated the gestational age with strong precision although, FL had better precision in terms of estimating the gestational age in the last trimester. The study results showed that, in case of $\mathrm{BPD}$, up to 35 th week the ultrasonic estimation of the gestational age varied 2 to 3 days when compared to LMP based gestational age and after that, the variation was 1 to 4 weeks. In case of FL, the ultrasonic measurement was 2 to 4 days behind in the second trimester and 2 to 3 days advanced in third trimester. In one study, it has been recorded that up to 20th week of gestation, FL provided a range of variation to estimate the gestational age of \pm 7 days, whereas after 36th week, this variation ranges up to \pm 16 days. ${ }^{19}$ In case of BPD the same study reports the variation of \pm 8 days before 20 th week and \pm 15 days after 24 weeks. ${ }^{19}$ Similar to our study findings, some study results suggest that, with the progression of the pregnancy period, BPD becomes less dependable to predict the gestational age. $^{20-22}$ On the other hand, FL shows correlation with higher precision with gestational age throughout the pregnancy and FL found to be significantly more accurate than BPD in the last trimester. ${ }^{11}$ In this study, when correlated with the LMP based gestational age, the FL predicted the same with a correlation coefficient of 0.998 and BPD predicted it with the correlation coefficient of 0.978 in third trimester. Although, in the second trimester, it has been found that, BPD was the superior predictor of the gestational age than the FL. In the second trimester, the correlation coefficient was 0.999 in case of BPD and 0.998 in case of FL when correlated with LMP based gestational age. Similar to this study findings, one research findings showed that, gestational age based on LMP found to be correlated with FL and BPD based gestational age with the correlation coefficient of 0.966 and 0.97 respectively. ${ }^{12}$ In another study, it has been found that, the correlation between gestational age estimated from FL was stronger than gestational age estimated from BPD when compared to the LMP based gestational age. ${ }^{23}$

\section{CONCLUSIONS}

Gestational age estimation is a widely practiced and very important application of ultrasound in antenatal care. Ultrasonic determination of fetal age depends on the measurement of fetal growth associated biometrics. The growth of the fetus varies according to the time of gestation. In this study among BPD and FL, the latter found to be more significantly representative of gestational age in the third trimester of pregnancy.

\section{REFERENCES}

1. Salomon LJ, Alfirevic Z, Da Silva Costa F, Deter RL, Figueras F, Ghi T, et al. ISUOG Practice Guidelines: ultrasound assessment of fetal biometry and growth. Ultrasound Obstet Gynecol. 2019 Jun;53(6):715-23.

2. Wegienka G, Baird DD. A Comparison of Recalled Date of Last Menstrual Period with Prospectively Recorded Dates. Journal of Women's Health. 2005 Apr;14(3):248-52. 
3. Kramer MS, McLean FH, Boyd ME, Usher RH. The validity of gestational age estimation by menstrual dating in term, preterm, and postterm gestations. JAMA. 1988 Dec 9;260(22):3306-8.

4. Shehzad K, Ali M, Zaidi S. Fetal biometry. Pakistan Journal of Medical Sciences. 2006 Oct 1;22:503-8.

5. Geirsson RT. Ultrasound instead of last menstrual period as the basis of gestational age assignment. Ultrasound Obstet Gynecol. 1991 May 1;1(3):212-9.

6. Chervenak FA, Skupski DW, Romero R, Myers MK, Smith-Levitin M, Rosenwaks Z, et al. How accurate is fetal biometry in the assessment of fetal age? Am J Obstet Gynecol. 1998 Apr;178(4):678-87.

7. ter Haar G. Ultrasonic imaging: safety considerations. Interface Focus. 2011 Aug 6;1(4):686-97.

8. Gameraddin M, Alhaj B, Alabdeen MZ. The Reliability of Biparietal Diameter and Femoral Length in Estimation the Gestational Age Using Ultrasonography. Journal of Gynecology and Obstetrics. 2014 Nov 22;2(6):112.

9. Falatah H, Awad I, Abbas H, Khafaji M, Alsafi K, Jastaniah S. Accuracy of Ultrasound to Determine Gestational Age in Third Trimester. Open Journal of Medical Imaging. 2014 Sep 1;4:126-32.

10. Gupta M, Sinha P, Sharma R, Srivastava KR. Comparison of Estimation of Gestational Age by Transverse Cerebellar Diameter with Biparietal Diameter in Third Trimester of Pregnancy. Journal of South Asian Federation of Obstetrics and Gynaecology. 2020 Nov 30;12(4):235-8.

11. O’Brien GD, Queenan JT, Campbell S. Assessment of gestational age in the second trimester by real-time ultrasound measurement of the femur length. Am J Obstet Gynecol. 1981 Mar 1;139(5):540-5.

12. Gameraddin M, Elhag B, Alabdeen M. The reliability of biparietal diameter and femoral length in estimation the gestational age using ultrasonography. 2014 Nov 16;

13. Palmer P. Estimation of fetal size and age (fetal biometry). In: Manual of Diagnostic Ultrasound. Geneva:WHO; 1995. p. 236-44.
14. O'Brien GD, Queenan JT, Campbell S. Assessment of gestational age in the second trimester by real-time ultrasound measurement of the femur length. Am J Obstet Gynecol. 1981 Mar 1;139(5):540-5.

15. Hearn-Stebbins B. Normal Fetal Growth Assessment: A Review of Literature and Current Practice. Journal of Diagnostic Medical Sonography. 1995 Jul 1;11(4):176-87.

16. Wegienka G, Baird D. A Comparison of Recalled Date of Last Menstrual Period with Prospectively Recorded Dates. Journal of women's health (2002). 2005 May 1;14:248-52.

17. Beigi A, ZarrinKoub F. Ultrasound assessment of fetal biparietal diameter and femur length during normal pregnancy in Iranian women. Int J Gynaecol Obstet. 2000 Jun;69(3):237-42.

18. Pretorius DH, Nelson TR, Manco-Johnson ML. Fetal age estimation by ultrasound: the impact of measurement errors. Radiology. 1984 Sep;152(3): 763-6.

19. Hadlock FP, Deter RL, Harrist RB, Park SK. Estimating fetal age: computer-assisted analysis of multiple fetal growth parameters. Radiology. 1984 Aug;152(2):497-501.

20. Wisser J, Dirschedl P, Krone S. Estimation of gestational age by transvaginal sonographic measurement of greatest embryonic length in dated human embryos: Estimation of gestational age. Ultrasound Obstet Gynecol. 1994 Nov 1;4(6): 457-62.

21. Chervenak FA, Skupski DW, Romero R, Myers MK, Smith-Levitin M, Rosenwaks Z, et al. How accurate is fetal biometry in the assessment of fetal age? American Journal of Obstetrics and Gynecology. 1998 Apr;178(4): 678-87.

22. Honarvar M, Allahyari M, Dehbashi S. Assessment of gestational age based on ultrasonic femur length after the first trimester: a simple mathematical correlation between gestational age (GA) and femur length (FL). Int J Gynaecol Obstet. 2000 Sep;70(3):335-40.

23. Egley CC, Seeds JW, Cefalo RC. Femur length versus biparietal diameter for estimating gestational age in the third trimester. Am J Perinatol. 1986 Apr;3(2): 77-9. 